Vol. 1 No. 2, Juli 2021, hlm. 147-152

DOI: https://doi.org/10.33330/j-com.v2i1.1246

Available online at http:// jurnal.stmikroyal.ac.id/index.php/j-com

\title{
PERANCANGAN PENGISIAN PADA DISPENSER DENGAN MEMANFAATKAN SENSOR DAN EMBEDDED SYSTEM
}

\author{
Alfianda $^{1}$, Muhammad Amin $^{2}$, Risnawati ${ }^{2}$ \\ ${ }^{1}$ Mahasiswa Prodi Sistem Komputer, STMIK Royal \\ ${ }^{2}$ Prodi Sistem Komputer, STMIK Royal \\ *email: stmikroyal13@gmail.com
}

\begin{abstract}
Nowadays, almost all of them use a dispenser, because of its practicality. But behind that there are several things that make the dispenser less efficient when taking drinking water from the glass, because the user has to press or turn the water tap in the dispenser. The working system of this tool is where the machine will run according to the commands obtained from the laser diode and the LDR sensor, the laser diode will reflect light that leads to the LDR. when the light reflected by the laser diode to the LDR is cut, it can be interpreted that the LDR and the laser diode detect or read the presence of an object in the form of a glass, automatically the two sensors instruct the controller to activate the water pump and the water pump will work to remove the water which will be filled in the glass that is placed in the dispenser with the volume of the glass used, the filling process and the end of filling will be displayed by the LCD and when filling the water the glass is full there will be a warning from the buzzer in the form of a sound. Users no longer need to press or turn the water tap when taking water from the dispenser using a glass.
\end{abstract}

Keywords: Dispensers;LDR Sensor;Diode Laser and Tools

\begin{abstract}
Abstrak: Pada saat ini masyarakat sekarang sudah hampir semuanya menggunakan dispenser, karena kepraktisan. Namun dibalik itu semua ada beberapa hal yang membuat dispenser kurang efisien saat mengambil air minum pada gelas, karena pengguna harus menekan atau memutar keran air yang ada pada dispenser. Sistem kerja dari alat ini ialah dimana mesin akan berjalan sesuai dengan perintah yang didapat dari Dioda laser dan sensor LDR, Dioda laser akan memantulkan cahaya yang mengarah pada LDR, pada saat cahaya yang dipantulkan Dioda laser ke LDR terpotong maka dapat diartikan LDR dan Dioda laser mendeteksi atau membaca adanya benda berupa gelas, secara otomatis kedua sensor tersebut memerintahkan controller mengaktifkan pompa air dan pompa air akan bekerja mengeluarkan air yang akan diisikan pada gelas yang diletakkan pada dispenser dengan volume gelas yang digunakan, proses pengisian dan akhir pengisian akan ditampilkan oleh LCD dan saat pengisian air pada gelas penuh akan ada peringatan dari buzzer berupa bunyi. Pengguna tidak perlu lagi menekan atau memutar keran air saat mengambil air pada dispenser menggunakan gelas.
\end{abstract}

Kata Kunci : Dispenser;Sensor LDR;Dioda Laser dan Alat 
Vol. 1 No. 2, Juli 2021, hlm. 147-152

DOI: https://doi.org/10.33330/j-com.v2i1.1246

Available online at http:// jurnal.stmikroyal.ac.id/index.php/j-com

\section{PENDAHULUAN}

Perkembangan teknologi saat ini sangat di perlukan bagi masyarakat dari semua kalangan di karenakan teknologi sudah menjadi kebutuhan masyarakat karena membantu pekerjaan rumah tangga dalam hal ini berupa dispenser air minum. Suplai air merupakan kebutuhan dasar setiap orang.

Air merupakan salah satu sumber daya alam yang sangat penting bagi kelangsungan kehidupan manusia dan makhluk hidup lainnya di bumi. Pentingnya air ini bagi kehidupan manusia dapat dilihat dari banyaknya unsur air yang terkandung pada tubuh manusia yang mencapai $70 \%$. Sumber air minum di perkotaan umumnya dipasok oleh Perusahaan Daerah Air Minum (PDAM) meskipun masih ada sebagian warga yang memperoleh air minum dari sumur galian. Seiring dengan pertumbuhan jumlah penduduk dan industri yang terus bertambah menyebabkan kebutuhan terhadap air minum juga semakin meningkat sehingga debit air yang dipasok PDAM ke pelanggan menjadi kecil dan terkadang tidak mengalir [1].

Dampak dari kekurangan air di karenakan penyediaan air jauh dari jangkauan, adapun alat yang dapat mempermudah penyediaan air minum adalah dispenser. Dispenser saat ini hanya menerapkan konsep air panas, air dingin dan air normal, belum adanya dispenser yang dapat melakukan pengisian secara otomatis. Oleh karena itu dispenser pengisi air minum di gelas otomatis menggunakan sensor ultrasonic dan sensor posisi resistif di dapat bahwa sistem sensor SFR04 mengaktifkan relay dan mematikan relay untuk menyalakan mesin air agar mengisi gelas dengan menggunakan system timer, walaupun gelas yang diujikan berbeda beda, tetapi kelemahan dari rancangan alat ini, pengaplikasian sensor sfr04 yang selalu error ketika berada dijangkauan 10-20 cm.

Selanjutnya Danel dan Wildian melakukan perancangan untuk mendeteksi gelas pada dispenser dengan menggunakan sensor fotodioda kurang cocok dalam mendeteksi gelas yang bening, karena cahaya yang dipancarkan dapat menembus, sehingga sistem belum bekerja. Setiap ada benda yang menghalangi sensor fotodioda, maka air akan langsung keluar dan ketinggian air diukur menggunakan sensor ultrasonik. Keluaran hasil pengukuran sensor ultrasonic tidak stabil hingga permukaan air pada cangkir mencapai $5 \mathrm{~cm}$ dari sensor, hal ini disebabkan bidang pantul air yang beriak [2].

Berdasarkan penelitian terdahulu, maka peneliti ingin merancang sebuah dispenser otomatis dengan memanfaatkan sistem kerja dari diode laser. Keunggulan dari rancangan alat yang akan dirancang, dispenser bisa menyala secara otomatis dan mati secara otomatis jika wadah minuman penuh. Selain itu wadah atau tempat minuman juga berbeda beda bentuk, sehingga tidak terfokus pada 1 jenis ukuran gelas. Sistem kerja dari rancangan alat yang akan dibuat ketika sensor ldr membaca data cahaya dari dioda laser maka data ldr akan mengirimkan sinyal ke controller dan cahaya dioda laser terhalang sehingga tidak mengenai sensor ldr. Jadi sistem pengisian dispenser akan aktif. Pada penelitian kali ini ada 3 buah sensor yang akan diaplikasikan pada rancangan alat menggunakan 3 jenis gelas dengan ukuran yang tidak sama [3]. 
Vol. 1 No. 2, Juli 2021, hlm. 147-152

DOI: https://doi.org/10.33330/j-com.v2i1.1246

Available online at http:// jurnal.stmikroyal.ac.id/index.php/j-com

\section{METODE}

Penelitian ini menggunakan metode penelitian pengembangan, experimental, simulasi dan expost facto. Adapun tahapan penelitiannya : 1) Analisa kebutuhan sistem; 2) Perancangan alat; 3) Analisis dan pengujian. Sehingga memperoleh hasil berdasarkan perancangan dan analisis pengujian di lapangan. Tujuan dari di buatkan alat ini adalah untuk memudahkan masyarakat dalam perancangan dispenser pengsisian air minum otomatis memanfaatkan sensor ldr dan embedded system. Berikut gambar diagram konteks tersebut :

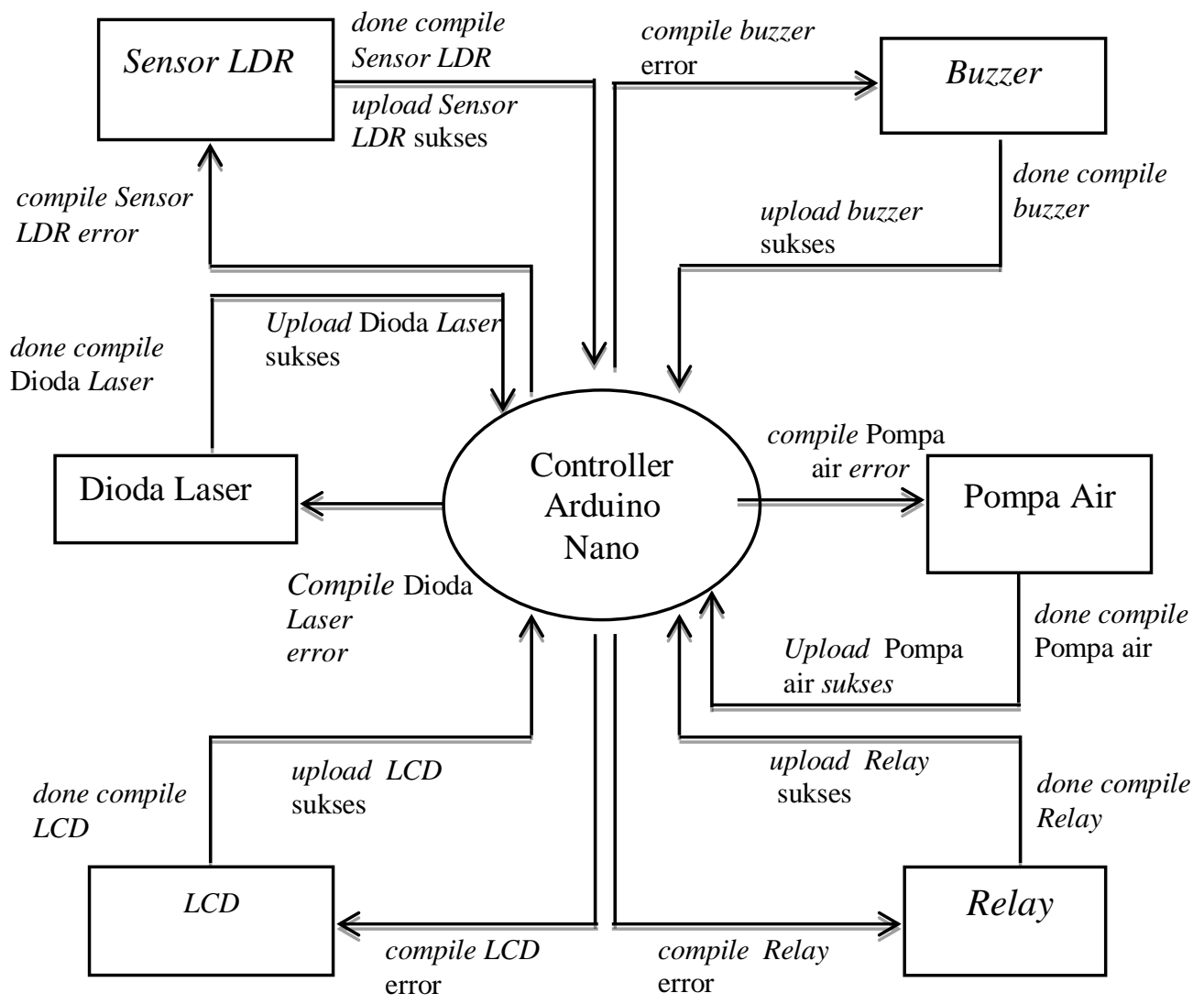

Gambar 1. Diagram Konteks

Perancangan antar muka (User Interface) adalah salah satu jenis perancangan yang digunakan untuk menggambarkan antar muka yang akan dipakai pada dispenser pengisian air otomatis pada gelas. Desain tampilan sistem berfungsi untuk acuan membuat user interface dalam implementasi sistem. 
Vol. 1 No. 2, Juli 2021, hlm. 147-152

DOI: https://doi.org/10.33330/j-com.v2i1.1246

Available online at http:// jurnal.stmikroyal.ac.id/index.php/j-com

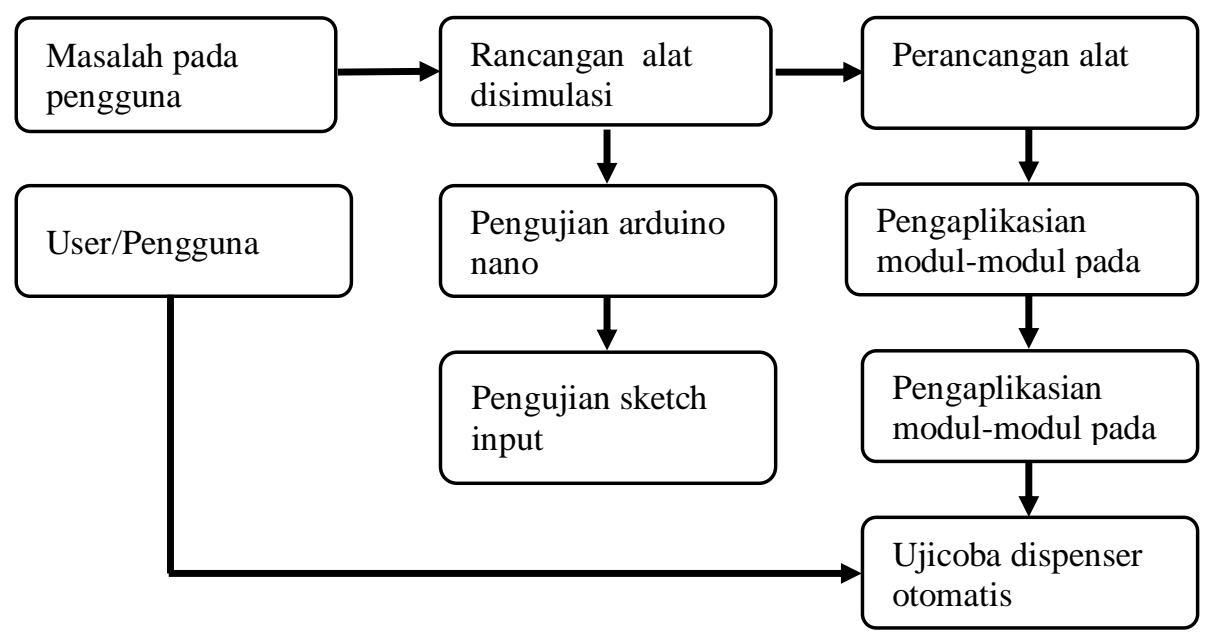

Gambar 2. Perancangan User Interface

\section{HASIL DAN PEMBAHASAN}

Rancangan yang dijelaskan sesuai dengan kebutuhan rumah tangga, dimana dispenser sangat di butuhkan oleh masyarakat disebabkan praktis, oleh karena itu masyarakat membutuhkan dispenser otomatis yang bisa mengisi air pada gelas yang berbeda ukuran secara otomatis tanpa harus membuka keran air pada dispenser. Pada pembahasan ini dijelaskan komponen-komponen yang terdapat pada alat saling berhubungan ke controller atau arduino nano dan untuk pengujian alat keadaan siap dipakai dimana diuji dihadapkan pada gelas ukuran yang berbeda.

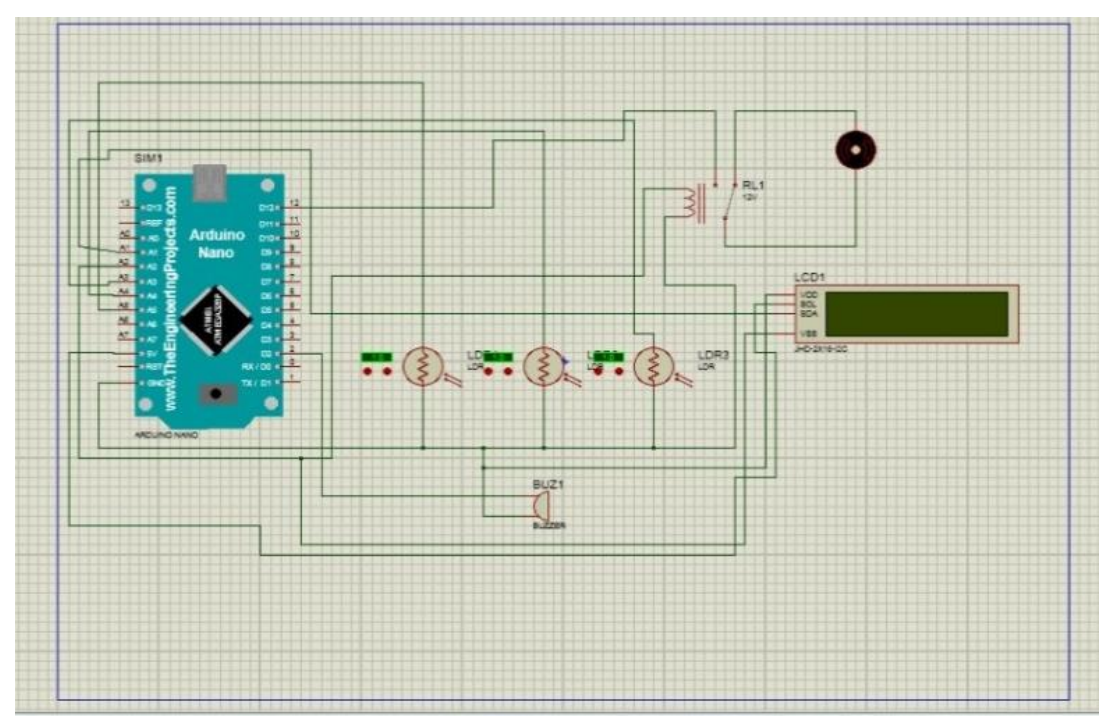

Gambar 3. Konfigurasi Keseluruhan Alat 
Vol. 1 No. 2, Juli 2021, hlm. 147-152

DOI: https://doi.org/10.33330/j-com.v2i1.1246

Available online at http:// jurnal.stmikroyal.ac.id/index.php/j-com

\section{Pengujian Alat}

Perancangan alat dispenser otomatis pengisian air pada gelas bekerja sesuai dengan perintah dan prinsip kerja yang diinginkan, dimana ketika sensor $L D R$ terkena cahaya dari dioda laser, maka mesin akan aktif untuk mengisi gelas sesuai ukuran sampai air penuh dan mesin akan mati, setelah itu tampil di layar LCD 1602 informasi status kerja alat pada saat proses mengisi, proses tidak mengisi dan proses pengisian sudah selesai mengisi. Hasil pengujian dengan memanfaatkan sensor dan embedded system seperti terlihat pada tabel 1 di bawah ini:

Tabel 1. Hasil Pengujian Alat di Lapangan

\begin{tabular}{|c|c|c|c|}
\hline \multicolumn{4}{|c|}{ Perintah I } \\
\hline Kondisi & Modul & Kondisi/nilai & Keterangan \\
\hline \multirow{5}{*}{$\begin{array}{c}\text { (Kondisi 1) } \\
\text { Saat tidak terjadi } \\
\text { pengisian air }\end{array}$} & Dioda laser & HIGH & \multirow{16}{*}{$\begin{array}{l}\text { Semua modul } \\
\text { bekerja aktif } \\
\text { sesuai dengan } \\
\text { perintah di } \\
\text { arduino.ide }\end{array}$} \\
\hline & LDR & $<215$ & \\
\hline & Relay & $>800$ & \\
\hline & Mesin air & Mati & \\
\hline & LCD & $\begin{array}{c}\text { Menampilkan } \\
\text { informasi }\end{array}$ & \\
\hline \multirow{5}{*}{$\begin{array}{l}\text { (Kondisi 2) } \\
\text { Saat proses } \\
\text { pengisian air }\end{array}$} & Dioda laser & HIGH & \\
\hline & LDR & $>215$ & \\
\hline & Relay & $>800$ & \\
\hline & Mesin air & hidup & \\
\hline & LCD & $\begin{array}{l}\text { Menampilkan } \\
\text { informasi }\end{array}$ & \\
\hline \multirow{6}{*}{$\begin{array}{c}\text { (Kondisi 3) } \\
\text { Saat proses } \\
\text { selesai pengisian } \\
\text { air }\end{array}$} & Dioda laser & HIGH & \\
\hline & LDR & $>215$ & \\
\hline & Relay & $<800$ & \\
\hline & Mesin air & NO & \\
\hline & LCD & Mati & \\
\hline & & $\begin{array}{l}\text { Menampilkan } \\
\text { informasi }\end{array}$ & \\
\hline
\end{tabular}

\section{SIMPULAN}

Pengisian gelas pada dispenser dengan memanfaatkan sensor dan embedded system tidak lagi menggunakan kran untuk mengeluarkan air, karena menggunakan sensor dan output yang di tampilkan pada $L C D$ dan suara yang dikeluarkan oleh buzzer memberitahukan pengguna dispenser bahwa gelas sedang melakukan pengisian atau pun sudah terisi penuh.

\section{DAFTAR PUSTAKA}


Vol. 1 No. 2, Juli 2021, hlm. 147-152

DOI: https://doi.org/10.33330/j-com.v2i1.1246

Available online at http:// jurnal.stmikroyal.ac.id/index.php/j-com

AIR," vol. 5, no. 1, pp. 18-23, 2018.

[2] B. M. Atmega and F. Hadary, "Perancangan Sistem Data Logger Pengisian Air Galon Otomatis," vol. 3, no. 1, pp. 1-8, 2017.

[3] V. No, "PENGISIAN GELAS PADA PROTOTYPE DISPENSER," vol. 4, no. 2, pp. 133-144, 2015. 